\title{
Grieving While Dissertating
}

\author{
Shelly Galliah
}

Dr. Shelly Galliah resides in the hamlet of Houghton, Upper Michigan, one of the snowiest and most remote places in the United States. At Michigan Technological University, she earnestly labors as an instructor and academic. Currently, she is interested in alternative forms of science communication, such as that of satire, as well as that offered by celebrities, particularly when they accommodate science and debunk manufactured scientific controversies. When not lecturing remotely in stressful ZOOMlandia, making every online mistake possible, Shelly may be found running or skiing on her local trails, accompanied by her two trusty canine compatriots: Darcie and Ruby. This essay, the first creative piece she has written in a long, long time, did not come easy, but the process was, indeed, therapeutic.

$\mathrm{I}$

$\mathrm{t}$ is July 10, 2018, in a dimly lit, rundown, humid hospital room in Moncton, New

Brunswick, Canada. My laptop precariously placed on an appropriated nurse's shaky supply table, I am fumbling with words. Reviewing a book on the conflict between morals and scientific knowledge is supposed to be a distraction. However, my thoughts are sporadically interrupted by the rasping of my dying 82-year-old mother, Florence, lying just a few feet away. My concentration dwindles, but my hands continue typing, churning out word salad for a subsequent ruthless editing.

Returning to the book, I find that the author's forgiving attitude towards the deeply religious leaves a bad taste in my atheist mouth. But I press on, critiquing his description of the schism between faith and science. As I struggle, the sweet, patient nurse, who has attended my mother's side for the last week, takes out her rosary and quietly suggests we pray. Together, she whispers, we may "lessen my mother's load" and prepare her for heaven. I trip over weak lies, confessing to forgetting the words, trying to silence the stalwart disbeliever in me. That small-town girl who refused to go to church in grade six, the one who realizes only death, not invocations to the Almighty, will ease Florence's pain. Seeing my mother's prone gray body precariously tubed between life and death, however, forces my capitulation. The irony of balancing the hard facts of medicine and the soft truths of faith stings while we dutifully commence: "Our Father, who art in heaven, hallowed be thy name, thy kingdom come, thy will be done, on earth as it is in heaven ..."

The previous day saw my unplanned arrival from upper Michigan, sweaty, rushed, and bewildered that my mother's seemingly minor accident-a tumble in scalding bathtub waters-had rapidly evolved into an urgent health crisis. Burns that would not heal, skin grafts that would not take, infections that stubbornly marched from her legs, to her urinary tract, to, finally, her heart and lungs. This is the explanation pieced

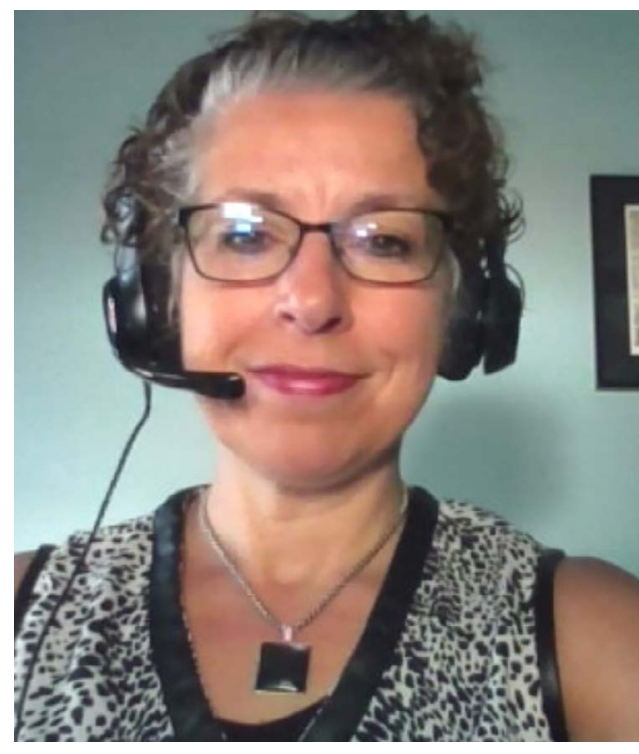

\section{ABSTRACT}

This personal essay, which moves between the present and the past, narrates the author's difficulty in grieving the death of not only her mother but also other family members who were lost during her pursuit of higher education. The piece critiques the workaholic culture of academia, particularly in graduate education, and comments on the availability of mental health resources for students. The author hopes that those reading the essay, especially those in academia, will recognize the importance of students' mental and physical health.

\section{KEYWORDS}

academia, graduate school, grief, grieving, mental health, family death 
together by me from the squad of bustling nurses regularly dressing and undressing my mother's hopeless wounds. At first, I am unreasonably irate that Mom, always part squirrel in her endless scurrying and getting-things-done, could not rest long enough to let her injuries heal. Then, I grow angrier at myself for being just like her, for so chasing my academic work that spring and early summer-from dissertation to book chapter to conference-that the seriousness of her sickness was lost in the shuffle. Bursting into that hospital room, crowded with the chatter of cousins and aunts and the mingled smells of perfume, urine, and stale food, I enter as the distant, neglectful, studious daughter, the one who forgot about her mother and who rarely came "home."

"I thought I knew how sick she was, but I didn't," repeatedly sputters out while my jetlagged self rushes to my barely sentient mother, whose eyes momentarily flicker. (When the nursing staff discovered I was travelling there, they reduced her pain medication so we could exchange our final goodbyes.) In obvious discomfort, my mother finally opens her eyes, scrapes out a barely audible "S-h-e-I-I-y, my Shelly" before grabbing my hand; the next hour is spent locked in her surprisingly strong arthritic grip as she murmurs my name. For the rest of that long day, Mom's mind drifts in and out of that room before finally succumbing to unconsciousness. To that first crucial step of being gone.

There is some consolation in meeting with her while she is still responsive. The tense six-hour car ride followed by an even edgier ten-hour plane trip were both dominated by one fear: if I lost another family member without seeing them first, I would not make it, not just through my PhD, but through life. Losing my mother without saying goodbye would finally break me.

$* * *$

Why was I working on that damn book review? Like other academics, I have assumed a perverse pride in juggling with and fretting over multiple projects. Regardless of whether we are graduate students, instructors, tenured or untenured professors, many of us often stupidly feel that if we are not ahead, we are necessarily behind on the next abstract, paper, presentation, project-all those subsequent benchmarks demonstrating our commitment both to the job and to our research. For me, an introvert with social anxiety and random panic attacks, academia has often been an unhealthy refuge. Hopping on the academic treadmill has enabled an escape not only from my past and my people, especially my dysfunctional family, but also from friends and acquaintances-those perceived obstacles to the work that always must be done.

However, family tragedies have persistently interrupted my stolid efforts to lose myself in research, to claim my membership in the community of academic workhorses. My attempt at the master's degree was met by misfortune, or maybe just bad luck: my sister, diagnosed with lupus and mental illness, was institutionalized for several suicide attempts; and my father, a longtime alcoholic and serious diabetic, was in and out of hospitals and drunk tanks when not conjuring up illegal schemes for quick cash. Once, on a moonshine-fueled bender, he slowly drove his Ford pickup truck into a graveyard, knocking over headstones that probably tumbled like so many awkward dominoes. These dramas were managed with the stoical, yet selfish, grace honed by a kid from the projects, one who believed education was her only salvation. Barricading myself from my family meant asking for no help and just gritting my way through school, working almost full time at a grocery store while writing my masters' thesis.

Pursuing my Ph.D. and extricating myself from my clan's inconvenient dramas meant fleeing far west to the wintry wasteland of Edmonton, Alberta. This move was only a temporary getaway, however. In the middle of my first dissertation attempt, my boyfriend had a bout with cancer and my father finally won the long game of drinking himself to death. A diabetic coma captured him before I could fly home. The funeral entailed two hours of cauterizing stares from judgmental relatives. Here, in the flesh, was the younger daughter from afar, the privileged one who, in choosing study over her kin, had no time for her modest Miramichi dad.

Things slowly fell apart after that trip: dwelling on my father's funeral and my boyfriend's cancer treatments substituted for concentration. The topic of nineteenth-century naturalism seemed especially remote and petty. Not able to return to my work, I drifted away from my dissertation, avoided my advisor's emails, and eventually dropped out of the program. Armed with only an MA, I labored in the adjunct trenches for several years in Alberta, Canada, before a move to Michigan offered an opportunity to enroll in a PhD program. Again. This was my final chance: attempt two must be successful. I had only to keep my edge, keep those family tragedies at bay.

Magical thinking might make me surmise that the curse of Graduate School 2.0 killed my remaining two family members and several of my aunts and cousins, all of whom passed during this period. In the first year of the program, overwhelmed by starting again at the ripe age of 40-something, reluctant to explain my choice to my family, I rarely called home. After years of seeing me teach the $4 / 4$ workload for little pay, they had unsettling questions about why their smart sister and daughter didn't have a real job, about why she had committed herself to this freshest academic hell. The tragicomedies of my mother's and sister's lives were even more depressing (and exhausting) now. Though my sister's mental health had improved, she was frequently ill from both lupus and the bad habits she would not abandon despite her slow-killing disease. My mother taxied between small towns in New Brunswick attending to my sister, pushing her octogenarian bones to exhaustion, developing the frequent dizzy spells that would eventually cause her accidental death.

Mom, trying to shield me from the trauma she knew would interrupt my work, lied about the severity of my sister's illness. Stage IV cancer abruptly took my sister during the end-of-second-term 
hustle. Stuck in the United States, shocked at her death, and quietly fuming at my mother, I did not ask for extensions on my papers nor request the immigration forms that would permit me to leave the United States. I did not speak to the graduate director. The day of my sister's funeral found me avoiding tears by playing with some trifling piece of the dissertation puzzle.

"Give us this day our daily bread; and forgive us our trespasses, as we forgive those who trespass against us; and lead us not into temptation but deliver us from evil. For thine is the kingdom, and the power, and the glory, forever and ever. Amen." Coerced into prayer once again, my lips conclude this simple supplication. On the second day, the nurse gently wipes my mother's face, wets her mouth, and adjusts her pillow, being ten times the caregiver I could be. Unconscious, but breathing, my mother lies attached to an unsettling maze of tubes and cords.

Unsurprisingly, I am sticking my head down once again, plodding through the book review, trying to disregard my mother's broken breathing. The fear of messing up Dissertation 2.0, I tell myself, compels me to work, but the truth is that lingering too long in the moment will imprint my mother's suffering on me. Temporarily renouncing my atheism, I pray for her to drift away.

But rather than drift away, my mother is adamantly refusing to go gently into that good night. All of that diet watching and furniture lifting and bridge walking have made her heart stubbornly strong. The same mother who once lugged a massive television up several flights of wooden stairs because she refused to ask "a man, any MAN" for help will certainly not surrender to death now.

As a Catholic who thinks suicide is a dreadful sin, Mom, of course, has not filled out the paperwork for a medically assisted suicide, but she has requested a DNR (do not resuscitate) order. In her mulish attitude both not to die and not to live, here she is still, after our supposed final goodbyes, drifting in medical limbo as the dutiful staff changes her dressings, administers her medications, and checks the readings on the machines.

"She's still hanging on," one of the nurses respectfully murmurs, as if my mother can hear her. Even in life, Mom was mostly deaf, ear drums busted from encounters with my father's drunken fists. "You need to tell her she can go now, Shelly, that she can end her suffering."

"I'll try," I answer tersely, "but I am sure she can't hear me. She is not there."

The nurse mutters another prayer before informing me that they'll "keep giving her morphine . . . for the pain. The doctor says that because of her age, she should pass shortly."
Waiting for her to pass is a dreary chore. My husband is absent: en route with our dog Darcie, he is trapped in Quebec's regular summer labyrinth of construction detours. There are no more visitors, no comforting relatives. Hearing about my isolation, my old high-school friend Terry meets me on Day Two. When he respectfully attempts to hide a grimace at the sight of my still, wan mother, I interject, "It's okay. You can stare. You know she is not even there anymore, right?, just the shell of her. She doesn't even realize I am here."

"What an awful sound," he remarks at the gurgling and gagging that stand for her breathing.

Terry and his macabre sense of humor I have known too long, so I preempt his dark thoughts by confessing, "You know what that horrid sound reminds me of, right? . . . a zombie . . . almost like one from the Walking Dead. Only these machines are keeping her going. Her soul, as Catholics like to call it, is definitely gone."

Terry transports me to a restaurant, where I eat my first real food in days, drinking too much white wine way too early. Halfway through my meal, it ironically occurs to me this is my first social outing in months. Previously, the only people who spent time with me were my advisor, my students, and my husband. Friends I certainly made no time for. My mother's illness forced me to do what had been neglected for so long: socializing with a friend, being human.

Upon my return, my mother is still unrelenting. The drive that coaxed tired, old me back into graduate school was obviously inherited from her. When the absentee doctor finally makes the rounds to my mother's room, I intercept his tedious refrain about it "not being long now" to blurt out, "She is not going to go like you want, peacefully and soon. ... Her heart is too resilient; she could hang on forever."

He drowns me with clichés about my mother being a feisty lady, "a real fighter," but the spreading infection means death is close. He then routinely yet sympathetically asks if I've had my time with her and exchanged my final goodbyes - these words being code for increasing her morphine dosage and granting her a final sleep.

The next few hours find me amidst whispering nurses administering more and more milligrams of morphine "for the pain," legally edging my mother towards the lethal tipping point. Tracking the dosages mesmerizes, yet frustrates me. Part of me is amazed at my mother's dogged refusal to die; another part is furious at her and her beliefs for forcing me to condone her accelerated passing. She continues hovering on the coma's precipice, her heart pumping vigorously, her pulse-ox at a ridiculously normal $98 \%$.

Puzzled about what and whom she is holding on for, the nurses anxiously mill about. Professional courtesy prevents them from admitting so, but they are waiting to clear the room of both my 
mother's body and mine. Because I have been sleeping, or should I say lying, in a cot by my mother's side, we are both squatting on valuable hospital real estate. Healthcare may be free in Canada, but beds are at a premium, so my mother and I have long outstayed our welcomes.

It takes two more long days for my mother to die. On Friday, July 13-of all days for a superstitious, yet devoted, Catholic to expire-her obstinate heart takes its last beats, and the machines stop their relentless humming and beeping. After Mom's death rattle continues for several minutes, I finally collapse into a corner for an ugly cry, blaming myself. When my relatives wouldn't make the decision, I was the one who agreed to all that morphine, to the removal of the breathing apparatus. I was the one who removed my mother from this earth, ignored my father's alcoholism, and missed my sister's funeral. The negligent daughter whose book learning always triumphed over family seemed responsible for all this pain, for all this loss.

My remorse intensified in the following weeks as we sorted out Mom's affairs, battling with banks, settling matters without a will, and organizing a service to appease my religious relatives. Throughout all this planning, though, I buried my misery: I ran every morning, completed afternoon errands, cleaned out my mother's apartment, had a glass of wine, went to sleep, started again. My rigorous academic schedule was replaced with an even more exhausting yet mundane one, one that avoided people and overt confrontations with pain.

After my return to Michigan, a few members of my dissertation committee encouraged me to take "the time I needed"; "your work can wait," they said in suitably soothing tones. But were they really sincere? What did "I need" mean, exactly? Would they have taken the time they required? My committee members were driven and stoical, the academics I had spent my life venerating: serious creatures bustling between meetings and really important projects. Surely, they must recognize there are chapters to write and deadlines to meet; there are mandatory student progress reports to complete; there are syllabi to prepare. They must realize that recovery is an indulgence, that resting would always take a back seat to my paralyzing fear of dropping out. They must know that the workaholic lifestyle they and their cohorts have modelled has made me alienate myself from others. That is, even if I had agreed to share my anguish, there was no one with whom to do so. There were no friendly departmental shoulders to lean on.

So, in true form, overwork was my solace again, which meant finally finishing that book review, sending out proposals, and chipping away at my dissertation. To all outward appearances, diligent Shelly was back on her feet, making progress again, but the pain was merely pushed down. That is, several weeks after my mother's death found me a quiet mess. Routine tasks would leave me staring blankly, stuck on the image of my gasping mother. The box of mementos carted all the way from New Brunswick remained untouched, parked in my dining room for almost five months. The phone was ignored when relatives or friends called; moments of joy and sadness were accompanied by a paralyzing fear of letting go. I could not, would not, cry again.

My grief, though, finally leaked out, just as it had previously done.

A few years before, in the middle of an important meeting on Title IX and the sexual harassment of one of our graduate students, which happened shortly after my sister's death, mourning got the best of me. In place of my opinion on the events emerged awkward tears, my stifled sadness for my sister irrationally colliding and then melding with my anger at how the department mishandled an altercation between a female LGBTQ victim and the student offender.

After my mother's death, my misery spilled at similarly inconvenient times. In class, a student's mention of his mother's cancer made me abruptly leave. In a routine meeting with my advisor, my breathing became difficult, waves of panic rising. Even my usually reliable therapy, my morning trail run, was punctuated by arbitrary swells of grief. A few jaunts found me lying down, waiting for the dizzying desolation to pass, my dog running partners hovering over me, confused by their human's temporary malfunctioning. Why are you so sad, human? So not ... right?

But I never, ever let myself fully go then, always stamping out the tears before they roiled into an uncontrollable storm.

It took the death of my mother to realize that fully succumbing to grief would mean acknowledging the cloud of depression that had hovered over me throughout graduate school. It took the contemplation of her passing to make me recognize the toxic culture of academia that often makes grief untenable because sadness is a sign of weakness and mental distress yet another side effect of student life.

Depression and anxiety in graduate school are so common, in fact, that they have become normalized, if not overlooked, by students, advisors, and faculty. My first time through graduate school, practically every student I knew was on some kind of medication, but I resisted following their lead, stupidly thinking they were weak. Twenty years later, during my second Ph.D. attempt, this ignorant attitude was echoed by a high-ranking professor. "Oh, everyone is stressed and depressed," she told me, boringly waving a hand away. "You have to find a way to deal with it." Other senior faculty members blithely volunteered these useful tidbits: "Oh, well, no one ever died from getting a Ph.D." Or, "You just need to get on with your work." In my experience, sympathetic souls concerned about students' mental health are rare, often those outsider professors on the sidelines who have chosen to live normal, balanced lives. 
Messages of support are, unsurprisingly, often mixed and unhelpful. For instance, "dealing with it" commonly means taking a night or maybe a week off before promptly returning to your schedule; such a directive implies avoiding both your emotions and professional help. Furthermore, flippant remarks about "everyone being in the same boat" do not acknowledge the prevalence of depression and anxiety, let alone the fragile mental health of many graduate students, which Colleen Flaherty has referred to as a crisis ("Mental Health Crisis" and "A Very Mixed Record"). In fact, the rate of depression and anxiety in graduate students may be at least six times higher than in the general population. Also, according to a 2019 editorial in Nature, in the publication's biennial survey of 6,300 international doctoral students, $36 \%$ of the respondents admitted to anxiety or depression ("The Mental Health of PhD Researchers"). Immersed in this culture, I didn't realize my mental distress until the tipping point of my mother's death.

The causes of this purported mental health crisis are hotly contested. Flaherty has attributed it to "social isolation, the often abstract nature of the work and feelings of inadequacy - not to mention the slim tenure-track job market" ("Mental Health Crisis"). Further investigating the problem, Nature Human Behaviour published a series of 28 blogs and columns in which various academics discussed the connection between stressed and anxious PhD students and dysfunctional academic culture. Common conclusions were that the pressure to publish or perish, the dwindling number of tenure-track jobs, unhealthy relationships with advisors, and the lack of support for alternative academic careers were placing unhealthy burdens on graduate students ("PhDs Under Publication Pressure"). The emphasis on performance, which in my case meant drafting a book review at your dying mother's bedside, contributes to mental health issues in fledgling academics.

This pressure to perform and publish has a deeper cause: the normalized workaholic culture of graduate school and academia in general. In my second semester, a respected professor explained that if graduate students really care, they must constantly push themselves. They are, she stressed, meant to be working 60-hour-plus weeks, making sacrifices for their research, their programs, and their advisors. They should be willingly forfeiting their mental and physical health to accomplish work that matters. This attitude was later seconded by a high-ranking graduate-school administrator, who sent a passive aggressive email reminding students of their fifty-plus-hour-a-week work obligation, which was tied to the university's most generous funding.

Graduate school even made my running, my only nonwork pastime, seem frivolous, a symptom of a weak academic commitment. Surprised students and professors alike would comment on my daily workouts. "When do you have the time?" they asked, hinting that I must be scrimping on my work. (Just this past year, I revised a dissertation chapter until 4:30 p.m. on Christmas Eve.) The dissertation process necessarily entailed creating circuitous routes that avoided my advisor's neighborhood for fear of being seen as goofing off. Grinding out runs became more stressful than joyful. Graduate school condones this abnormal guilt because academics often pay only lip service themselves to work-life balance. Students, then, might feel ashamed to step away from the books to maintain their mental and physical health.

Still, any challenge to academia's culture of overwork must be accompanied by transparent moves to eliminate the stigma surrounding not only taking time off but also admitting mental unwellness. My wounds took overly long to heal because making adequate time for my grief and confessing my depression would have been embarrassing. Many academics might also be afraid of admitting their mental health struggles because of fears of losing promotions or of being negatively judged by colleagues. The dread of appearing vulnerable is passed down to their graduate students, who are reluctant to discuss their mental health with their seemingly stoical superiors.

And when my defeat was finally admitted, there was nowhere to turn. That is, my situation was aggravated by both my department's and my university's minimal mental health resources for graduate students. At the time of this writing, there is no content in our program's handbook about coping with traumatic events or about strategies for maintaining mental health. The category "Graduate Student Resources" includes information about the program's office, student mentors, professional-development seminars, reading groups, job-placement assistance, writing and technology resources, and the library. In short, this handbook sends the message that the only necessary ingredients for student success are academic and financial. The missing wellness content also suggests that either mental health issues do not exist or they are not legitimate concerns.

When I recently accessed the graduate student website, it fared no better. On the page for the most relevant student information, the first link was "Bill Payment," followed by employment opportunities and financial assistance. The alphabetization unfortunately placed "Student Life" at the bottom, which then opened up a page revealing a happy, relaxed student sitting with a dog amidst a sunny, grassy setting, an idealized image of the work-life balance the site itself ignores. After "Get Involved" and "Explore," there are some generic university-wide links to medical support and "counselling and wellness services."

In contrast, the generic student page, usually accessed by undergraduates, features a large, central button for "Counselling and Wellness Services." The implied message is clear: undergraduates, we take your health and wellness seriously; graduates, not so much. Whereas university administrators tend to their flock of undergraduates, alert to any signs of mental distress, graduate students are supposed to be dispirited, teetering on the edge of demoralization. 
A further problem exists with university-wide mental wellness services: graduate students, whose assistantships are tenuous at best, might be reluctant to access these resources for fear of encountering those they teach. The whiff of mental illness might undermine graduate teaching assistants' credibility in the classroom, making their lives even more challenging.

When my friend Terry read a draft of this essay, he alarmingly expressed, "Holy Crap! . . . If you took this work environment and put in any other industry, there would be never-ending human-resources meetings that tried to fix this problem. The whole environment reminds me of the tale of Sisyphus." Unfortunately, that rock is still being rolled up the hill; there are no plans to overhaul toxic academic culture any time soon. The best grad students can do is learn how to survive it.

Therefore, my essay ends with an urgent plea for all readers who are out there suffering and who have suffered to recognize my story as an object lesson. You may find that advisors and faculty are unsympathetic. You may find, like me, that your own intransigent nature too easily embraces the workaholic culture of your program and too easily neglects your mental health. Even if wellness resources do exist, you might be ashamed to admit your need of them.

Although resisting academia's unhealthy culture is difficult, please try to allocate a healthy time and space for your mental wellness. If your problems and your circumstances make you reluctant to speak with your advisor, venture outside your circle and search out other students, faculty, administrators, and relatives who seem sympathetic. Connect with those who recognize that your feelings are genuine and not easy excuses for procrastination. Ask for extensions and for extra time; choose a genuine respite and not a temporary stop; talk to professionals; take any necessary medication. Budge that recalcitrant dial of culture change.

Revisiting my mother's death while drafting, writing, and revising this essay has slowly forced both a recognition and a necessary shift. I have reluctantly accepted my identity as an introverted, partially depressed, workaholic recluse who has chosen academia because she will always find more comfort in books (and in dogs) than in people. Now, though, when I feel like escaping the academic world, even if it is not often enough, I heed my body and my mind. When the fear of wasting time surfaces during my runs, I duly silence it by pounding out an extra mile.

Now that the Ph.D. is completed, most days have more sun, but there are still shadows. But when that sorrow spills, I no longer turn off the valve but instead allow myself to cry for those family members who were never fully mourned. When sadness overcame me while revising this essay, for instance, the keyboard was abandoned so tears could roll, blamelessly.
My friend and semiretired colleague, Karla, one of the most selfless, balanced professors I know, one of those rare academics who has always willingly made time for many students, causes, and committees, confessed something surprising recently: she cries every day, for as long as necessary, and then calmly gets on with her tasks. (She also knits and loafs and wallows whenever the spirit moves her.) These tears have admittedly been more frequent in these unsettled and stressful COVID times, she admits, yet she still sheds them for the sake of her mental health. Sage words, indeed, not only for academics, but for all of us.

\section{Works Cited}

Flaherty, Colleen. "Mental Health Crisis for Grad Students." Inside Higher Ed, 6 March 2018, https://www. insidehighered.com/news/2018/03/06/new-study-saysgraduate-students-mental-health-crisis.

Flaherty, Colleen. "A Very Mixed Record on Grad Student Mental Health: New Studies Find Variation by Departments, with Findings of Significant Rates of Depression and Anxiety." Inside Higher Ed, 6 December 2018, https:// www.insidehighered.com/news/2018/12/06/new-researchgraduate-student-mental-well-being-says-departmentshave-important.

"The Mental Health of PhD Researchers Demands Urgent Attention." Nature, 13 November 2019, https://www.nature. com/articles/d41586-019-03489-1.

"PhDs Under Publication Pressure." Nature Human Behaviour, 10 October 2019, https://www.nature.com/collections/ ijfdfjhjef. 